\title{
A new species of Neopsis (Hemiptera: Cicadellidae: Tartessinae), with new distribution records from Paraná State, Brazil
}

\author{
Alexandre Cruz Domahovski ${ }^{1}$ \\ 1 Universidade Federal do Paraná (UFPR), Setor de Ciências Biológicas, Departamento de Zoologia (DZ00). Curitiba, PR, Brasil. \\ ORCID: http://orcid.org/0000-0003-4588-4236. E-mail: domahovskiac@yahoo.com.br
}

\begin{abstract}
Neopsis campestris sp. nov. is described and illustrated based on male and female specimens collected on native grassland at the Guartelá State Park, Paraná State, Southern Brazil. New distribution records are presented for three previously known species, Neopsis aurea Takiya \& Dietrich, 2017, Neopsis myrceugeniae Takiya \& Dietrich, 2017 and Neopsis robusta Linnavuori, 1965, representing the first known records of the subfamily Tartessinae for Paraná State. A distribution map is also provided to illustrate the locality data of specimens studied herein.
\end{abstract}

Keywords. Auchenorrhyncha; Distribution map; Neotropical region; Neopsini; Taxonomy.

\section{INTRODUCTION}

The leafhopper subfamily Tartessinae Distant, 1908 currently comprises four tribes: Neopsini Linnavuori, 1978 (Neotropical), Stenocotini Kirkaldy, 1906 (Australian), Tartessini Distant, 1908 (Australian, Indomalayan) and Thymbrini Evans, 1936 (Australian). Neopsini is a poorly known and morphologically enigmatic group which can be distinguished from the other Tartessinae in their relative small body size ( $>7 \mathrm{~mm})$; markedly short head, with inconspicuous fronto-lateral sutures; ocelli well below the crown-face transition; absent transverse carina between ocelli; obsolete antennal ledges; accessory setal row between front tibial rows AD and AV; several cucullate setae between the larger macrosetae on hind tibial row; hind wing veins RP and MA confluent distally; and submarginal vein not extended onto jugum (Hamilton, 1983; Takiya \& Dietrich, 2017).

Neopsini currently comprises two genera, Lonnia Hamilton, 1983, with two species from Chile, and Neopsis Oman, 1938, which includes eleven previously described species distributed from the Caribbean islands to Southeastern Brazil (Takiya \& Dietrich, 2017). Members of the tribe are rarely collected, and the few known species are scarce in zoological collections. Information on the life history and host plant associations for this group are still unknown. In Brazil, Neopsis was recently recorded in the Amazonian region, Cerrado and montane Atlantic forest (Takiya \& Dietrich, 2017). This paper provides the first distribution records of four tartesine species for Paraná State, Southern Brazil (Fig. 1), representing three previously described species, Neopsis aurea Takiya \& Dietrich, 2017, Neopsis myrceugeniae Takiya \& Dietrich, 2017 and Neopsis robusta Linnavuori, 1965, and a new species, Neopsis campestris sp. nov. These are also the first tartesine species to be collected in the Araucaria moist forest and the native grasslands of the Brazilian Atlantic forest.

\section{MATERIAL AND METHODS}

Specimens examined in this study are deposited at the Coleção Entomológica Pe. Jesus Santiago Moure, Universidade Federal do Paraná, Brasil, Curitiba (DZUP); Coleção Entomológica Prof. José Alfredo Pinheiro Dutra, Departamento de Zoologia, Instituto de Biologia, Universidade Federal do Rio de Janeiro, Brasil, Rio de Janeiro, (DZRJ); and Museu de Zoologia da Universidade de São Paulo, Brasil, São Paulo (MZSP).

Morphological terminology follows Dietrich (2005), except in the following terms: frons, clypeus and gonoplac (= third ovipositor valvula), which follows Mejdalani (1998). Techniques used for the dissection of the male genitalia follow Oman (1949), with a few modifications described in Cavichioli \& Takiya (2012). Illustrations were prepared according to the procedures outlined in Domahovski \& Cavichioli (2019). The distribution map was generated using the online tool SimpleMappr (Shorthouse, 2010). Labels were transcribed between quotation marks, with a backslash $(\backslash)$ indicating line breaks. 


\section{RESULTS}

\section{Taxonomy}

\section{Neopsis campestris sp. nov.}

Figs. 1-21

Diagnosis: Head (Figs. 3, 4) bright yellow with transverse red band between eyes; frons and clypeus black in males and bright yellow in females (Fig. 13); ventral margin of male pygofer (Figs. 5, 6) with short preapical process, acute and curved dorsally; style (Fig. 8) narrow, preapical lobe moderately developed, not strongly produced posterad; posterior margin of aedeagus (Figs. 9-10) with well developed triangular lobe sub basally; apex (Fig. 10) with weak lateral serrations and without lateral processes.

Measurements $(\mathrm{mm})$ : Holotype $\left(\sigma^{\prime}\right)$ : total length 4.7. Paratypes (ơ), 4.7-4.8; (\%), 5.1-5.5.

Color:Head (Figs. 3, 4, 12, 13) brightyellow with transverse red band between eyes; frons and clypeus black in males (Fig. 4) and bright yellow in females (Fig. 13). Pronotum (Figs. 2, 11) with lateral and posterior margins and midline broadly red, contrasting with disc, cyan. Scutellum and exposed part of mesonotum (Figs. 2, 11) bright yellow. Ventral side of thorax, abdomen and legs yellow. Forewings (Figs. 2, 3, 11, 12) with three orange longitudinal bands, one along commisural margin and base of clavus, one along claval suture and one medially on corium, areas between bands cyan; veins cyan; distal third of membrane brown. Abdominal tergum brown or black in males and yellow in females.

Description: External morphological characters as in the genus description of Takiya \& Dietrich (2017).
Male terminalia: Male pygofer (Figs. 5, 6) relatively long, dorsal and ventral margin almost parallel; ventral margin with short preapical process, acute and dorsally curved; apex slightly tapered, rounded, dorsal margin bearing several minute tooth-like processes. Subgenital plates (Figs. 5-7) as long as pygofer; lateral constriction well developed; ventral surface with many setae. Style (Fig. 8) narrow, with preapical lobe moderately developed, but not strongly produced posterad; apophysis distad of lobe sinuate and denticulate, toe of foot-like apex rounded and weakly sclerotized; group of lateral setae present just distad of lobe. Connective (Fig. 8) with median anterior lobe well produced anterad of lateral arms. Aedeagus (Figs. 9, 10), in lateral view, with atrium narrow; posterior margin with well developed triangular lobe subbasally and few small setae just above of lobe; shaft relatively short; apex (Fig. 10), in dorsal view, with weak lateral serrations and without lateral processes. Other characters as in generic description of Takiya \& Dietrich (2017).

Female terminalia: Sternite VII (Figs. 14-16) lateral margins slightly tapered posterad and culminating in pair of slender, short processes; posterior margin approximately straight between processes with shallow medial v-shaped notch. Pygofer (Figs. 15-16) moderately long; with few macrosetae near ventral margin and anteroventral portion; apex with pair of short and rounded lateral lobes. Ovipositor (Figs. 15-16) slender, evenly curved; apex extended slightly beyond pygofer in repose. First valvifer (Fig. 17) small and triangular-shaped. First valvula (Fig. 17) with ventral interlocking device distinct on basiventral half of blade; apex (Fig. 18) gradually tapered and acute. Second valvula (Fig. 19) dorsal margin with approximately 18 teeth; apex (Fig. 20) with ventral margin with denticles. Second valvifer (Fig. 21) elongated, ca. 3,5 times higher

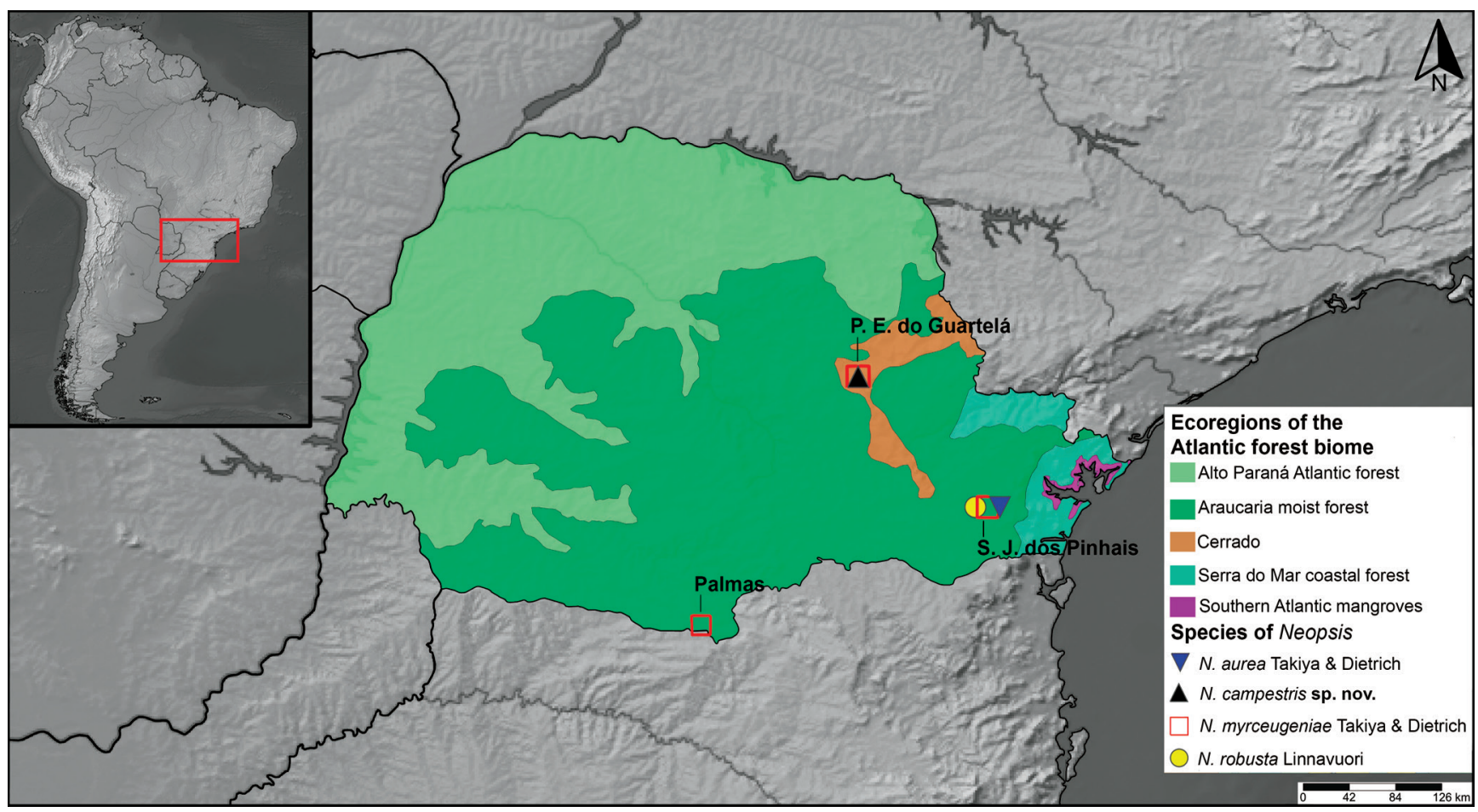

Figure 1. Distribution map of Neopsis species on different ecoregions of the Atlantic forest in Paraná State, Brazil. 
than long. Gonoplac (Fig. 21) with dorsoapical margin long, straight, almost parallel to ventral margin; ventral margin broadly rounded, with spaced setae near ventral margin; external surface with dentiform cuticular projections near apex and ventral margin; apex rounded. Other characters as in generic description of Takiya \& Dietrich (2017).

Etymology: The specific epithet refers to the native grasslands of Southern Brazil where the type series was collected.

\section{Material examined}

Holotype male: "Brasil, Paraná, Tibagi \ P.[Parque] E.[Estadual] do Guartelá, $1000 \mathrm{~m} \backslash 24^{\circ} 33^{\prime} 47^{\prime \prime} \mathrm{S} 50^{\circ} 15^{\prime} 26^{\prime \prime} \mathrm{W}$ $\backslash$ 21-24.XI.2016 Sweep \A.C. Domahovski leg." (DZUP).

Paratypes: $7 \sigma^{7} \sigma^{\pi}, 10$ 우, same data of holotype $\left(20^{7} \sigma^{n}\right.$, 2 ㅇ, DZRJ; 1 o", 1 , MZSP; 4 ơ o", 7 \%ᄋ, DZUP); 1 \%, same data as preceding, except "23-24.II.2017 Luz" (DZUP).
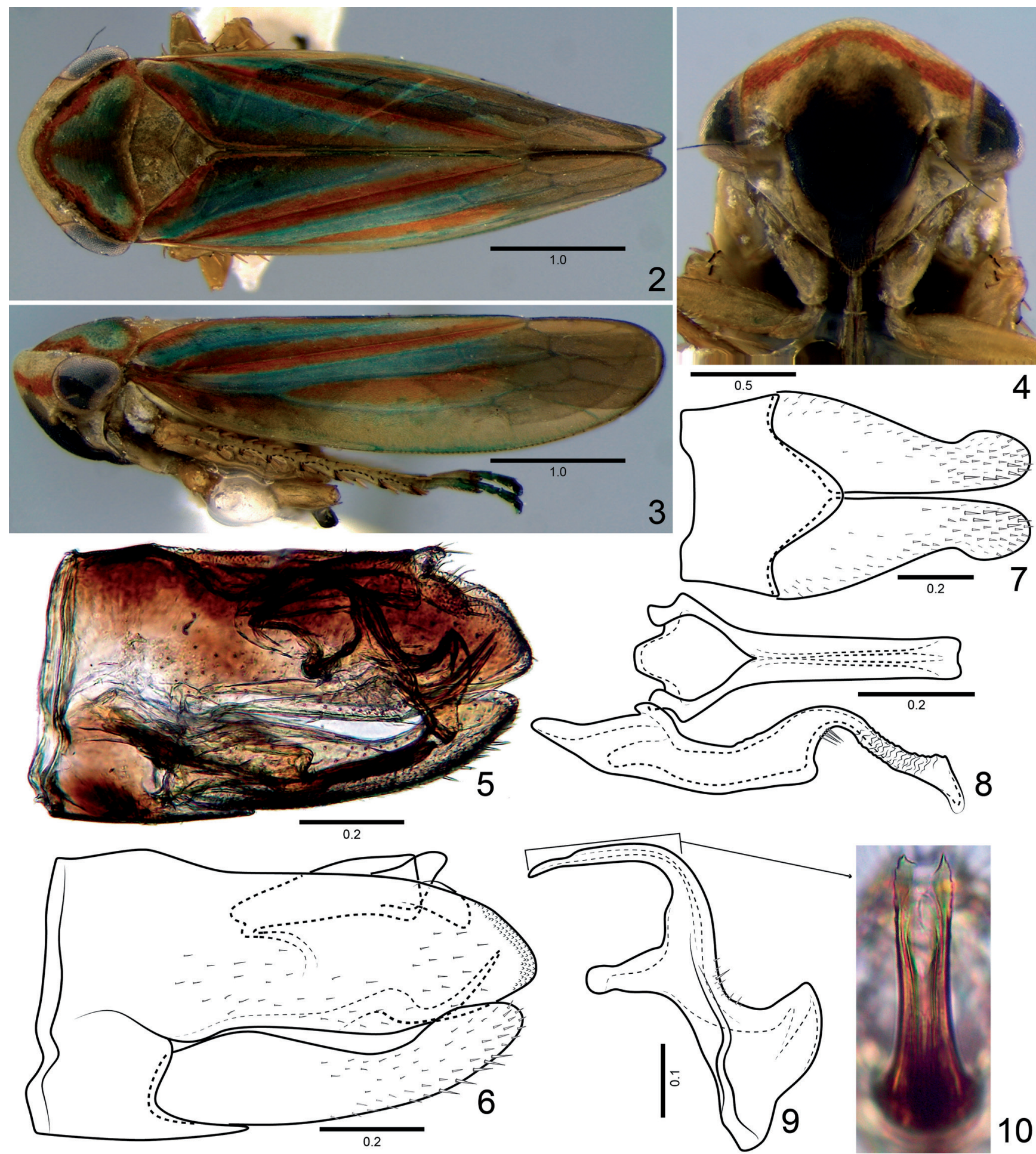

Figures 2-10. Neopsis campestris sp. nov., holotype male. (2) habitus, dorsal view. (3) habitus, lateral view. (4) head, ventral view. (5) genital capsule, lateral view. (6) pygofer, valve, anal tube and subgenital plate, lateral view. (7) valve and subgenital plate, ventral view. (8) connective and style, dorsal view. (9) aedeagus, lateral view. (10) enlarged view of apex of aedeagal shaft. Scale bars: in $\mathrm{mm}$. 
Notes: The new species keys out at couplet 7 in Takiya \& Dietrich's (2017) key. Distinctive features of N. campestris sp. nov. include the bright red pronotal margins; the body length $<5.0 \mathrm{~mm}$ (males); the style with preapical lobe weakly developed, not distinctly produced posterad; and the posterior margin of atrium of aedeagus with a large lobe. However, the new species can be separated from N. villaricensis Takiya \& Dietrich, 2017 in lacking the dorsal spine near base of aedeagal shaft and lacking apical triangular processes. Neopsis campestris sp. nov. differs from N. robusta Linnavuori, 1965 in having the male pygofer with a short preapical process, acute and curved dorsally; and aedeagus with a well developed triangular lobe on the posterior margin.
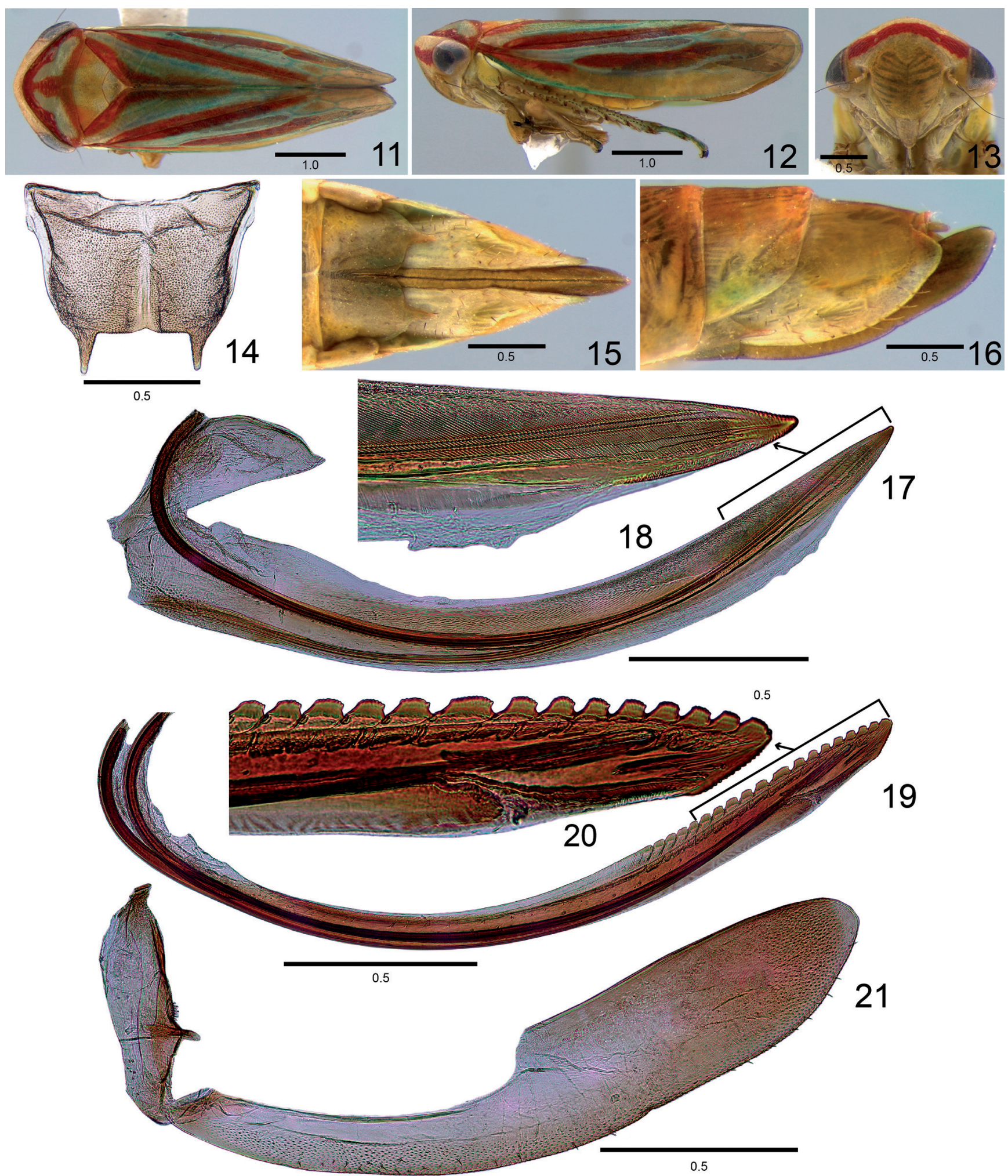

Figures 11-21. Neopsis campestris sp. nov., female paratype. (11) habitus, dorsal view. (12) habitus, lateral view. (13) head, ventral view. (14) esternite VII, ventral view. (15) distal portion of abdomen, ventral view. (16) distal portion of abdomen, lateral view. (17) first valvifer and first valvula, lateral view. (18) apical portion of first valvula. (19) second valvula, lateral view. (20) apical portion of second valvula. (21) second valvifer and gonoplac, lateral view. Scale bars: in mm. 

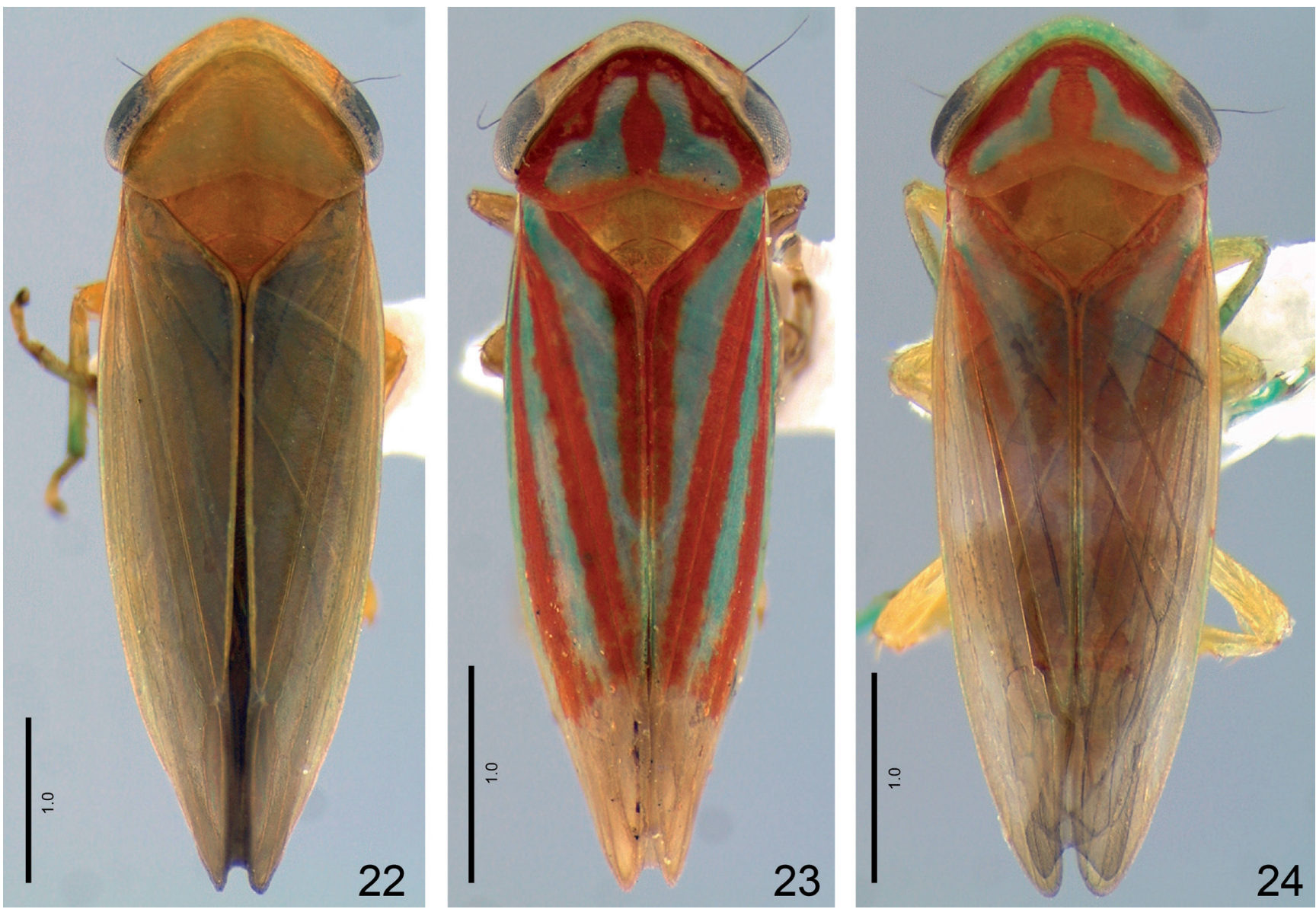

Figures 22-24. Habitus, in dorsal view, of the three species of Neopsis recorded from state of Paraná, Brazil. (22) N. aurea Takiya \& Dietrich. (23) N. myrceugeniae Takiya \& Dietrich. (24) N. robusta Linnavuori.

\section{Additional material examined}

Figs. 22-24

Neopsis aurea Takiya \& Dietrich, 2017. Brazil: Paraná [new record]: $90^{\prime} 0^{\prime \prime}, 9$ 우, São José dos Pinhais, $25^{\circ} 36^{\prime} 18^{\prime \prime} \mathrm{S}$, $49^{\circ} 11^{\prime} 37^{\prime \prime}$ W, sweeping net, A.C. Domahovski leg, (DZUP).

Neopsis myrceugeniae Takiya \& Dietrich, 2017. Brazil: Paraná [new record]: $10^{7}, 8$ $\%$, São José dos Pinhais, $25^{\circ} 36^{\prime} 18^{\prime \prime} \mathrm{S}, 49^{\circ} 11^{\prime} 37^{\prime \prime} \mathrm{W}$, sweeping net or malaise trap, A.C. Domahovski leg, (DZUP); $10^{\circ}, 10$ 우, Tibagi,

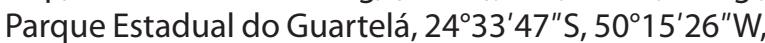
sweeping net, A.C. Domahovski leg, (DZUP); 1 o", Palmas, $26^{\circ} 33^{\prime} 26^{\prime \prime} \mathrm{S}, 51^{\circ} 32^{\prime} 32^{\prime \prime} \mathrm{W}$, malaise trap, A.C. Pereira, (DZUP).

Neopsis robusta Linnavuori, 1965. Brazil [new record]: Paraná [new record]: $70^{7} 0^{\prime \prime}, 9$ \&ᄋ, São José dos Pinhais, $25^{\circ} 36^{\prime} 18^{\prime \prime} \mathrm{S}, 49^{\circ} 11^{\prime} 37^{\prime \prime} \mathrm{W}$, sweeping net or malaise trap, A.C. Domahovski leg, (DZUP).

\section{Notes on distribution, collecting methods and color variation in $N$. robusta}

This study provides the first records of the subfamily Tartessinae for Paraná State, Brazil, which now represent the southernmost records for the genus Neopsis (Fig. 1).
$N$. aurea and $N$. robusta are also recorded, for the first time, in the Brazilian Atlantic Forest and the Araucaria moist forest, in the municipality of São José dos Pinhais. Neopsis myrceugeniae was collected in three different municipalities, São José dos Pinhais (Araucaria moist forest), Palmas (Native Grassland), and Tibagi (Parque Estadual do Guartelá), which encompasses native grassland, Cerrado and fragments of Araucaria moist forest. Neopsis campestris sp. nov. was collected only in Tibagi by sweeping shrubs and grasses. Neopsis aurea, N. myrceugeniae and $N$. robusta were mainly collected by sweeping in the understory of the forest, and a few specimens were collected using malaise or light traps.

The males of $N$. robusta studied herein (Fig. 24) do not have a dark to black scutellum, as observed in specimens from Bolivia and Ecuador. However, several other features, such as the morphology of male genitalia, the shape of the posterior margin in the female sternite VII, overall body size, and coloration match the description and illustrations of this species. Therefore, the color of the scutellum will be assumed as intraspecific variation in this study.

\section{ACKNOWLEDGMENTS}

The author thanks the Conselho Nacional de Desenvolvimento Científico e Tecnológico (CNPq) for their fi- 
nancial support (process 140815/2017-1). Special thanks to the editorial team of Papéis Avulsos de Zoologia and two anonymous reviewers who made useful contributions to an earlier version of this manuscript.

\section{REFERENCES}

Cavichioli, R.R. \& Takiya, D.M. 2012. Description of a new species of Wolfniana and new records of Rotigonalia (Hemiptera: Cicadellidae: Cicadellinae) from the state of Amazonas, Brazil. Zoologia, 29(1): 85-88.

Dietrich, C.H. 2005. Keys to the families of Cicadomorpha and subfamilies and tribes of Cicadellidae (Hemiptera: Auchenorrhyncha). Florida Entomologist, 88: 502-517.

Domahovski, A.C. \& Cavichioli, R.R. 2019. Three new species of Daveyoungana Blocker \& Webb (Hemiptera: Cicadellidae: lassinae: Hyalojassini) from Brazil. Zootaxa, 4571(4): 477-488.
Hamilton, K.G.A. 1983. Revision of the Macropsini and Neopsini of the NewWorld (Rhynchota: Homoptera: Cicadellidae), with notes on intersex morphology. Memoirs of the Entomological Society of Canada, 123: 1-223.

Mejdalani, G. 1998. Morfologia externa dos Cicadellinae (Homoptera, (icadellidae): comparação entre Versigonalia ruficauda (Walker) (Cicadellini) e Tretogonia cribrata Melichar (Proconiini), com notas sobre outras espécies e análise da terminologia. Revista Brasileira de Zoologia, 15(2): 451-544.

Oman, P.W. 1949. The Nearctic leafhoppers (Homoptera: Cicadellidae). A generic classification and check list. Memoirs of the Entomological Society of Washington, 3: 1-253.

Shorthouse, D.P. 2010. SimpleMappr, an online tool to produce publicationquality point maps. Available: https://www.simplemappr.net. Access: 25/06/2020.

Takiya, D.M. \& Dietrich, C.H. 2017. New species and new subfamily placement of the enigmatic neotropical leafhopper tribe Neopsini (Hemiptera: Auchenorrhyncha: Cicadellidae). Entomologica Americana, 122(3):435-450. 